\title{
The Use of Social Networks in Curbing HIV in Higher Education Institutions: A Case Study of the University of Zambia
}

\author{
Harrison Daka1 ${ }^{*}$, W. James Jacob2 ${ }^{*}$, Paul Kakupa1, Kapambwe Mwelwa1 \\ ${ }^{1}$ Department of Educational Administration and Policy Studies, University of Zambia, Lusaka, Zambia \\ ${ }^{2}$ Institute for International Studies in Education, School of Education, University of Pittsburgh, Pittsburgh, PA, USA \\ Email: ‘bhamudak@yahoo.com, ^wjacob@pitt.edu
}

How to cite this paper: Daka, H., Jacob, W.J., Kakupa, P. and Mwelwa, K. (2017) The Use of Social Networks in Curbing HIV in Higher Education Institutions: A Case Study of the University of Zambia. World Journal of AIDS, 7, 122-137. https://doi.org/10.4236/wja.2017.72011

Received: March 2, 2017

Accepted: June 23, 2017

Published: June 28, 2017

Copyright $\odot 2017$ by authors and Scientific Research Publishing Inc. This work is licensed under the Creative Commons Attribution International License (CC BY 4.0). http://creativecommons.org/licenses/by/4.0/

\begin{abstract}
The AIDS epidemic has affected every aspect of Zambian society and is recognized as the greatest public health challenge of the past 30 years. Nevertheless, education can generate hope in the face of the epidemic using different methods, including social networks. This article investigates the positive and negative impacts of social networks on the spread of HIV at the University of Zambia (UNZA). The research study included survey-based oral interviews with 280 UNZA students. During the course of the study, we realized that efforts have been and are being put in place at UNZA to use online social networks to spread news about HIV and AIDS and how to stop its transmission. Findings showed that most participants felt that social networks hastened the spread of the virus among social media users. Despite social networks having a few positive effects, the results of our study indicate that the negative effects far outweigh the positive effects.
\end{abstract}

\section{Keywords}

Social Networking, Social Media, Facebook, Online Relationships, HIV Education

\section{Introduction}

HIV and AIDS are a global concern that transcends race, culture, occupation, gender, and age. It also represents a universal challenge with broad sociocultural, -economic, -political, -ethical, and -legal dimensions. In the last 30 years or so, much has been learned about the impact of HIV and AIDS on society. Currently, the epicenter of the disease is in Sub-Saharan Africa and specifically in the Southern African Development Community countries. When consi- 
dering the implications of HIV in higher education, it is important also to consider its impact on young adults.

Coombe and Kelly reported that universities in Africa are high-risk institutions for transmission of HIV [1]. This situation is caused by several factors, including the "sugar daddy" practice (having sex with older men for socioeconomic gain), sexual experimentation, prostitution on campus, unprotected casual sex, gender violence, multiple concurrent partners, and similar HIV highrisk activities that contribute, to a greater or lesser degree, to the transmission of the infection. Furthermore, universities are commonly located in large and/or capital cities where the prevalence of HIV tends to be highest.

The University of Zambia (UNZA) is located in Lusaka, the capital city of Zambia, a Sub-Saharan region that has the highest HIV seroprevalence in the world [2] [3]. According to the 2001 Zambia Demographic and Health Survey (ZDHS), HIV prevalence in Zambia was $16 \%$ in the 15 - 47-year-old age group, while the urban prevalence in Lusaka was 22\% [4] [5]. The 2007 ZDHS showed a lower national frequency (14.3\%), but the prevalence in Lusaka remained high.

UNZA students, faculty members, and staff was at 15,500 in 2014, consisting of 12,750 undergraduate students (8000 attending full time and 4750 attending by distance education), 250 postgraduates, 2000 support and technical staff, and 500 academic staff. At the beginning of the AIDS epidemic in the 1980s and 1990s, UNZA health services offered limited HIV and AIDS interventions. Although $76.1 \%$ of UNZA students were aware of HIV and AIDS, over half of them (53.9\%) reported that they had participated in unprotected vaginal sex, $3.0 \%$ in anal sex, and $20.9 \%$ either anal or oral sex. Having multiple sexual partners was common [6].

In 2012, approximately 1.1 million Zambians had HIV (950,000 adults and 160,000 children) [3]. As of June 2009, almost a quarter million of them, i.e., $70 \%$ of those in need received antiretroviral treatment (ART) [7]. However, Zambia has shown some progress with the rising number of young adults who show more responsibility in their sexual behavior, unmarried young people who remain abstinent, and a decreasing number who have sex before marriage. Zambia's HIV prevalence appeared to peak in the mid-1990s. Since then it has come down a little, but remains stubbornly high at around $12.7 \%$ of the adult population, making Zambia the seventh worst-affected country in the world [3]. Real progress has been made in extending ART, but satisfactory progress has not yet been made in stemming the increasing number of persons infected with HIV. The number of people infected with HIV continues to escalate at an alarmingly high rate. In 2009, there were 82,700 new adult infections [7]. Alarming for that year was that for every adult who died from AIDS-related illnesses, two more were infected. Most of the new HIV infections come from heterosexual intercourse involving those believed by others not to be involved in extramarital sexual activities. There is an increased risk of being infected if Zambians have sex with multiple partners or any form of casual sex with a partner who is neither a spouse or a cohabiting partner. 
In this study, we examined the impact of social networks on the spread of HIV at UNZA. This article first provides a literature review of studies conducted on the role of social networking and its impact on the spread of HIV. Next, we highlight the methods used in data collection and the findings from the study. The conclusion provides recommendations and suggestions for future research.

For years, researchers, scholars, scientists, doctors, and other interested people are looking for answers concerning the spread of HIV. Many researchers, policy makers, and educators have and continue to advocate for the use of education as a social vaccine to the pandemic [8]. Even after hundreds of billions of dollars of research investment, scientists have yet to find a cure. HIV and AIDS continue as a key topic of discussion in the media and various social networks. Can education really help to reduce the spread of HIV? Do social networks have an impact on the spread of the disease?

The aim of this study is to discuss education, social networks, and their relationships to address HIV and AIDS. This study provides merit to those involved with education at all levels, including researchers, policymakers, planners, and practitioners. It highlights the positive and negative influences of social networks in facilitating discussions and interactions about HIV between users. Our findings also highlight awareness that not all information available on social network platforms is factual and/or helpful.

There are reports that show how Zambia has made positive strides to prevent the spread of the AIDS endemic. Gareth reported that Zambia is aggressively doing what it can to stop the spread of the disease [9]. The national response in Zambia involves publishing and disseminating flyers and posters warning people about the perils of HIV and AIDS, promoting abstinence, being faithful to people's partners, and using condoms. The media also plays an important role in HIV-related activities, such as promoting HIV awareness through mass media outlets (e.g., TV, Internet, radio, and newspapers) and by conducting occasional site visits to elementary schools, which are later broadcast through several media outlets.

Social networks are also tools that governments and organizations can use to prevent the spread of HIV. The government approved the National HIV/AIDS/ STI/TB Policy in 2005, which stipulates how government institutions are to implement the policy nationwide. In addition, other organizations have also done some sensitizations on abstinence, male circumcision, and condom use as ways of combating the epidemic.

At the present, the term social network is defined differently by scholars. For instance, Marino defines social network to include a group of people who share similar interests, ideas, values, norms, education levels, and many other forms of identity [10]. He further defines social networks as a social structure made up of individuals called nodes, who are connected by one or more types of interdependency such as friendship, kinship, beliefs, financial exchange, social class, sexual relationships, and knowledge. Social networks have become a common phenomenon over the past decade in both developed and developing countries 
because people continuously want to identify themselves with a particular group or status. Examples of such Internet social networking services or social networking sites include Facebook, Twitter, Pinterest, LinkedIn, MocoSpace, 2go, and itsmy.

Having established the major ways by which HIV is transmitted between individuals and defined social networks, the following sections look at the effect of social networks on HIV prevalence rates in higher education institutions. Social networks can create a favorable environment that nurtures social linkages to the extent that may lead to sexual relationships [11].

Although social media can spread unlimited information instantaneously to broad audiences across vast distances, it should be noted that social media is a great disseminators of misinformation. Marino explained that most of the information shared on social networking websites contain many falsehoods and distortions. One such falsehood circulated in the social media, especially on Facebook fan pages, is a statement that "if your boyfriend does not ask you for sex, do not think that he is an angel or holy; just know that he is getting it from somewhere else" [10]. Obviously, this kind of information can be very retrogressive in the fight against HIV, as it openly encourages the assumption that relationships are always based on sex.

In some cases, relationships are pre- and extramarital, involving partners who are in other committed relationships. For instance, the Zambian Sunday Mail newspaper exposed a married woman who had an affair with a married man. The relationship, which started on Facebook, ended up being sexual [12]. If one of the partners is infected by HIV and unsafe sex is practiced, the virus has a substantially higher likelihood of infecting the other(s).

Social networks on the Internet are a sophisticated phenomenon that has made people's life easier in many ways. Communication with anyone and anywhere on the planet is at the touch of a button. However, it has been alleged that social networks also encourage the spread of HIV/AIDS. Presario explained that over half of Internet users in developed countries had met in person with people they had befriended through the Internet [11]. He went further by stating that at least half of these people ended up having sexual encounters or relationships with friends they met through social media. Presario's research also revealed that given the rate people in developing countries are being exposed to the Internet, this trend will continue in the next few years. This means that more people are meeting over the Internet, even in developing countries such as Zambia, and a large proportion of these people end up having sexual encounters.

\subsection{Why Do People Join Social Networks?}

There are many reasons why people join social networks and in some cases, the formation of these networks is unavoidable. We will discuss two primary reasons why people join social networks: to interact with other wage-labor migrants or "educationists" or to build professional network ties.

Wage-labor migrants or educationists are people who work far away from 
their homes for long period of time (e.g., teachers, miners, and military personnel) and tend to form or find themselves in employment-related social networks to have comfort away from home. People by nature tend to work well around individuals with whom they feel comfortable based on their race, tribal grouping, political affiliation, religion, and so on. According to Haour-Knipe and colleagues, migrant workers, who leave their families behind, often face an upward battle of fitting in and finding acceptance among the various locations of their employment and travels [13]. The resulting isolation may increase their vulnerability to HIV. However, as social human beings, migrants create their own social networks and relationships, which are often unfamiliar and of short duration, particularly among single migrants. In addition to individual risk factors of the HIV/AIDS infection, migrant labor (soldiers, teachers, and miners) is an environmental risk factor that includes recreational outlets like beer bars, discotheques, high availability of commercial sex workers (CSW), and exposure to pornographic materials. These may increase their vulnerability to HIV infection.

Because these migrant workers live far away from their dear ones, they develop social and cultural networks locally, which provide strong emotional support and influence group behavior and activities with peers. Workers create their own social networks and relationships to fulfill their physical and emotional needs. Munachaka explained that "many people especially men are at risk of HIV infection because their work involves spending long periods away from families" [14].

Men are especially vulnerable when they are separated from their families and, in the end, they seek company and sex from girlfriends or female CSW; thus exposing themselves and their sexual partners, including their spouses, to HIV. The situation worsens if men in the same social network opt to go and have sex with the same HIV-positive CSW, which means that this CSW could potentially infect multiple partners. The Ministry of General Education has a policy that sometimes posts teachers in remote and distant locations from their homes for periods of at least two years. Based on this scenario, posting teachers in remote or distant locations from their home can lead many teachers into forging new social networks that often leads to sexual intercourse outside of marriage and often with multiple partners.

Educators and researchers who often commute for work are also susceptible to the virus. Some educationists often travel out of town to assess learning in institutions and some researchers travel to do presentations, participate in workshops, and be visiting scholars in cities-even countries-different from their own.

Similar to migrants, social networking, relationships, and other factors mentioned above can also involve students (especially higher education students), which makes them vulnerable to the transmission of the virus. This will automatically become a drawback in the education sector because the infected student will not be attending lectures as often as he/she should. This, in turn, may jeopardize their long-term performance in the classroom.

Establishing professional social ties and networks is the second primary rea- 
son people join social networks. HIV and AIDS cases are often reported in professional social networks. People often spend time together in their workplaces and they tend to develop intimate feelings out of routine. In most cases, they become involved in casual sexual encounters. This can be fatal, especially in cases where partners do not know their HIV status. Therefore, HIV can spread faster in such social and sexual networks because people do not stick to one social network in their lifetime [15]. Thus, in the case of lecturers/teachers in teacher training institutions, e.g., they can have three different social networks, which potentially may cause the exposure of more teachers and students to HIV. This happens to the extent that a man can have one sexual partner at the workplace based on a similar educational level, one at home-his legal wife by marriage, and perhaps even at church. Thus, if a man has more than one sexual partner in his social network other than his wife, it means that the HIV contracted by one member of a network might spread to all three individuals and to their other networks [16].

Similar to adults, students in schools are bound to form their own social networks within their communities and their respective Internet social networks. Some students, especially teenagers, also create their social and sexual networks with the opposite sex. Peter noted that students in their teens tend to be more attracted to the company of a member of the opposite sex than their own [17]. The formed social networks have a two-way effect; they can either enhance knowledge of the HIV pandemic or result in the creation of relationships which may lead into sexual activity thereby increasing the spread of HIV.

\subsection{Positive Effects of Social Media Sites in Reducing the Spread of New HIV Infections in Higher Education Institutions}

Although the public education system should be an obvious venue to educate the youth about sexual health, lectures are not organized regularly and only few students in higher learning institutions receive comprehensive sexual health education. On that premise, people saw the urgency of using another tool for this important education. As millions of youth access the Internet regularly [18], educators realized that the Internet, especially social networking websites, could be an important tool for providing an improved sexual health education to students.

The rationale behind the use of social media in mitigating the spread of sexually transmitted infections (STIs), including HIV, lies in the sociological focus of social media. Heckathorn et al. noted that even though many infectious diseases are spread through casual contact and contagion, HIV results from risky behaviors that involve close and often intimate contact [19]. As such, the transmission of HIV is structured by the social relationships within which these contacts are imbedded. Therefore, this makes social networking websites especially suitable to further study about the spread of new HIV infections. Furthermore, it is as important to study whether social media or social networking websites can also be a tool to prevent the spread of HIV among sexually-active young students in higher learning institutions. Accumulating evidence has proved that so- 
cial media can be used to fight the spread of STIs and promote good sexual health [20] [21].

Bull and colleagues conducted a study in the United States to determine whether STI-prevention messages delivered via Facebook are effective in preventing the increasing unsafe sexual behavior at two and six months among the 1578 participants in a randomized-controlled trial of condom use [20]. The results showed that the rate between those who received sensitization messages on condom use and the rate of adoption was more than those who did not receive it (intervention $68 \%$ compared with control $56 \%, p=0.04$ ). Six months later, the proportion of sexual acts protected by condoms increased to those sensitized compared with those not (intervention $63 \%$ vs. control $57 \%, p=0.03$ ). Therefore the study clearly showed "that social networking sites may be venues for efficacious health education interventions" [20]. Thus, it is possible for health-care providers to reach millions of youth through social networking websites.

Furthermore, social networking can give youth in higher learning institutions access to rich information that is beneficial for their health and behavioral changes. This practice is already implemented in the United States. In 2009, the National Institutes of Health spent US\$12.1 million for an intervention in seven universities to create a Facebook page for scientists [22]. This network allowed researchers to readily search and share information and streamline lists of their published articles, academic publications, and other information for the benefit of many, including students in higher learning institutions [22]. By doing this, they automatically helped followers of the Facebook page to engage in healthseeking behavior.

Therefore, social networking websites are suitable platforms upon which diverse information such as HIV testing events, encouraging adherence to ART, and delivering appointment reminders by text messages to improve retention in care [23]. Social networking can also improve people's lives by sharing useful information with friends such as good and responsible sexual behavior.

Some studies show that computer- and Internet-based interventions contribute to improved sexual health outcomes for youth and other at-risk groups. Technology-based programs, therefore, can have effects equivalent to nontechnology-based programs for sexual health [18]. The information in social networking websites such as the risks of having multiple sexual partners and drinking or drug use during sex can positively influence those who engage in generally risky sexual behaviors. Social media can also neutralize the social stigma on health. In the US, the Stigma project uses Facebook to lower the HIV-infection rate and neutralizes social stigma through education using social media and advertising.

Social networks on the Internet act as a platform that young people use to discuss issues that affect them; therefore, youth tend to learn more about the disease through this platform. For example, Facebook has become an important tool for many HIV/AIDS activists who want to spread the information about the infection. There are many groups focusing on HIV/AIDS in many social media websites, which increase young people's awareness. We came across some 
groups on Facebook: "I pledge to face HIV/AIDS by donating my FB Status" (http://www.facebook.com/HIV.AIDS.awareness) and the "HIV/AIDS awareness" group, which emphases its members to think positively in case of HIV/ AIDS. Young people are able to discuss HIV/AIDS issues freely in these groups.

It can be inferred that social media (social networking websites) is apparently a new approach to technology-based interventions in reducing the spread of HIV and other STI. It is also a valuable tool for reaching and sensitizing millions of young people through online media to avoid engaging in risky sexual behavior. By applying this action, we can reduce the spread of new HIV infections among youth in higher learning institutions.

\subsection{Negative Effects of Social Networks on HIV Education}

While social networking websites can spread HIV-prevention information faster than any other media websites, there is a major concern regarding their use. Several social consequences have been linked to the continuing use of social media such as Facebook. For the purpose of this study, only those that relate to the spread of HIV/AIDS will be discussed.

First, it is important to note that social networking is only one obstacle in the fight against HIV. This is because of its considerable effect on human behavior. It encourages unsupervised and inappropriate casual relationships. Many people are turning to social media to make anonymous friendships. Over time, these interactions tend to escalate into sexual relationships [24]. A US study found that social media is a risky environment for STI; there was a very high incidence of sexual relationships among online partners as a result of social media efficiency in facilitating the interaction of partners [25]. A related study conducted in 2006 among 270 homosexuals discovered that $48 \%$ had had sex with a partner whom they found online with only 53\% reporting having used a condom [26]. In 2012, there was an increasing number of STI patients in New Zealand who admitted that they used social media to have sex with more than 50 partners in three months [27].

Social networking websites have also been linked to personality and brain disorders as well as addictive behaviors. There is no question about these websites' potential to introduce one to pornography, which eventually becomes a habit or disorder [28]. There is a large amount of nudity and sexual involvement expressed openly on these websites. Unsuspecting youths post their erotic pictures in anticipation of comments, much to the amusement of potential sexual hook-up partners and predators. As a result, these high-risk tendencies expose more people to HIV infection.

Most social networking websites have discussion for a and advice corners. Needless to mention that, in most cases, what is shared on these websites is often amateurish and informal advice. This information and advice may be so misleading that those who receive it end up in worse situations. In 2011, a 15-yearold Lusaka schoolgirl committed suicide. She was allegedly advised to do so by some friends who had commented on her Facebook status in which she expressed frustration with life following a quarrel with her dad [29] This is just one 
example of how dangerous social networks can be.

The addiction to social media may further lead to feelings of loneliness or anxiety when one has not visited the $\mathrm{Web}$ site. This works directly on the mind as social media provide temporary social gratification. Feelings of loneliness, in turn, can predispose one to unhealthy and risky practices such beer drinking. Beer drinking may further expose one to HIV high-risk sexual activities [30].

Social networking can also make young people avoid seeking specialized help from relevant institutions. Social media purports to have the answers to virtually every problem, including health-care problems. Instead of going to a medical facility, social network users prefer to post their problems online. For example, a youth may post a status on Facebook such as, "I have a terrible headache. Pals, what should I do?"However, because this question is obviously directed to the wrong audience, their feedback may be amateurish and misguiding. It may include statements such as, "You need to relax, go and see a movie, or just drink some bottles of Castle Lager and the pain will go." Some friends may even suggest sex as remedy. This aspect of social networking can have a very serious implication for the spread of HIV because carriers may remain unaware of their status, yet they can unknowingly infect others and re-infect themselves [31].

No one monitors what young people talk about in their groups and on the Internet. Some youth may have free access to pornographic social media websites, which may lead them to engage in high-risk sexual activities. Peer pressure in these social groups and social media websites is high. Young people can easily become involved in drug abuse; they might end up sharing needles and drinking alcohol, which also lead to unprotected sex. Because of the factors mentioned, we see that there has been an increase in the number of young people contracting HIV in recent years in Africa. Many scholars argue that HIV/AIDS remains a significant problem for those attending higher education in Africa because many students at this age group are sexually active young adults [32] [33].

Therefore, it is important to note that most people who access social networks are young people who are in their exploratory age. Those who had accessed pornography through the Internet would not want to keep it to themselves and are bound to share it with other members of their social networks. Because of this, young people tend to want to experiment and hence engage in early sexual activities. In 2009, according to the Central Statistical Office, the Zambia Sexual Behavior Survey revealed that in Zambia the age of people who experience their first sex was 19.5 years for the males and 17.5 years for the females. This age range is unarguably the age of a high school student or a first-year student at a college or university. Then again, because most of their sexual encounters were in secret, the chances that they used a condom the first time they had sex may be slim [17].

\section{Methodology}

\subsection{Participants}

The survey was administered to 285 UNZA students (see Table 1) who were 
Table 1. Survey participant demographic statistics.

\begin{tabular}{ccc}
\hline & Frequency & Percentage \\
Sex & 121 & 43 \\
Male & 169 & 57 \\
Female & & \\
Age & 182 & 65 \\
Under 24 years & 98 & 35 \\
24 years and over & & 67 \\
Marital status & 189 & 28 \\
Single & 78 & 1 \\
Married & 2 & 2 \\
Separated & 6 & 2 \\
Divorced & 5 & 65 \\
Widow/widower & & 35 \\
HIV status known & & \\
Yes & 98 & \\
No & 182 & \\
\hline
\end{tabular}

enrolled in the "Introduction to HIV and AIDS Issues in Education" course. The study was conducted towards the end of the course, after participants had learned concepts related to HIV and AIDS and the important role education plays in the national response to the epidemic. All participants were in their final year of study at the undergraduate level. This was important, as they would have experienced some of the issues raised in the study. Members of the research team introduced the study to participants and to obtain consent for participation; five students declined to participate, giving us a response rate of $98 \%$.

\subsection{Ethical Issues and Institutional Review Board Approval}

This research touched on sexuality issues, which are often considered taboo to discuss in many traditional Zambian cultures. Some resistance was encountered, especially during interviews. Occasional reservations were expressed by some participants when they were willing to respond to our questions initially, and then afterwards asked that their identities be kept anonymous. The study was approved by the Institutional Review Board of UNZA, through the Department of Educational Administration and Policy Studies.

\subsection{Analysis}

Data analysis used both quantitative and qualitative methods of analysis. Participants have been evaluated and compared with each other to shed light on the use of social media in higher learning institutions and how they deal with issues related to HIV and AIDS. Analysis was completed after surveys were collected from participants and the data was fully input, cleaned, and coded for trends, 
patterns, and anomalies. Quantitative data was organized using Excel and SPSS software.

\section{Findings and Discussion}

The composition of the respondents was $43 \%$ male and $57 \%$ female. Most of the respondents (65\%) were of young age (below 24 years) and 35\% were above 24 years. This showed that most of the students are alumni. The results revealed that $98 \%$ of students have Internet access and $90 \%$ of those who have readily available Internet access are active in online social networks. Eighty percent of the respondents said that at some point in their online experience they have met someone in person whom they first met over the Internet.

If Presario's findings that most people who meet on networks end up having sexual relations are put into practice in this context, it means that a large proportion of Internet users actually end up having sex, thus increasing their risk of contracting the virus if they do not use protective measures [11]. The situation was more challenging because $65 \%$ of all students who are active in social networks do not even know their HIV status, which is similar to those who do not participate in social networks.

Sadly, some interview subjects said some friendships that started through social networks ended up becoming sexual relationships immediately after the first meeting. This study focused only on college students because they perceive this trend as being the most up-to-date mode of making friendships. Social networks are perceived to be a desperate way to create new friends. Our research conducted with university students showed that the primary reasons why the majority of young people join social networks is mainly to have new friends and befriend famous and/or good-looking people of the opposite sex. These social networks have a provision for face uploading on one's social network account so that they are able to be seen by others in a positive light. Young people use social networks as a resource to fulfill their psychological and social needs. The differences between the sexes in these needs demonstrate that they play a compensatory role; males use them to cover emotional aspects and reinforce self-esteem, while for young females, the relational function prevails. Our survey showed that the most active age groups on these social networks are the students in their twenties, with a majority of them in college. Most of them stated that they accessed the Internet from their phones. Therefore, it was clear that many young students (Table 2) access social networks. The study also showed that most social network users use their phone, which shows that they can communicate anytime and also many are those aged $18-24$ years (see Table 3 ). As they access this type of media for communication, the results showed also that the majority are those who are single (Table 1). The results also showed that most participants met via social networks through organized courses and lectures, compared with meeting through social networks of famous personalities, classmates, religious leaders, relatives, and friends. From the previous literature discussed above, which states that most online friendships end up in sexual relationships, 
Table 2. Distribution of participants' activity in social networks.

\begin{tabular}{ccc}
\hline & Frequency & Percentage \\
\hline Internet access & & \\
Yes & 274 & 98 \\
No & 6 & 2 \\
Active in social networks & & \\
Yes & 252 & 90 \\
No & 28 & 10 \\
Met in person after initial contact via social network & & 80 \\
Yes & 224 & 20 \\
No & 56 &
\end{tabular}

Table 3. Primary source of Internet access based on age.

\begin{tabular}{cccccc}
\hline & Phone & Laptop & Desktop & Internet café & Total \\
\hline 18 - 24 years & 156 & 23 & 0 & 3 & 182 \\
25 - 30 years & 16 & 13 & 1 & 2 & 32 \\
31 - 40 years & 18 & 22 & 2 & 1 & 43 \\
Over 40 years & 1 & 9 & 3 & 1 & 13 \\
Total & 191 & 67 & 6 & 7 & 280 \\
\hline
\end{tabular}

it may be assumed that some of these friendships might also have resulted in similar relationships. In addition, both parents and educators should be open to allowing the youth to discuss such issues [6].

From the interviews, we found that most female students searched for famous personalities and course coordinators on Facebook, and sought to meet them in person later. Some interview subjects in this study admitted that they were lured by individuals related to prostitution industries to become a CSW for financial purposes as an act of desperation. Normally, women are the most vulnerable because they want to follow the current fashion and need money to do so. This explained the large number of girls who became mothers at an early age; some of them are even in the sex industry to earn a living. In most cases, the connection is available through the Internet. When these women befriended people who are already connected with the prostitution industry, they were gradually groomed to the idea and mentored until they become CSW and unfortunately expose themselves to the dangers of HIV/AIDS [17].

\section{Conclusion and Recommendations}

Following this study among UNZA students, it can be concluded that social networks may indeed hasten the spread of the virus, especially in developing countries such as Zambia. Despite having a few positive effects, the negative effect of social networks outweigh the positive effects. Some efforts to use social networks to spread news and information about HIV/AIDS are already being 
done to stop the transmission of the virus. However, these efforts have been largely undermined by the negative effect of social networks. It would be a very difficult task to control this trend because these social networks are now deeply rooted in society, especially among youths.

Our results showed that compared with adults over 24 years old-some of them not actively involved in social networks-youth younger than 24 years had Internet access and were active in social networks. The most active age group in social networks is the age that is most desperately interested in the opposite sex. Therefore, older men and women try to take advantage of these vulnerable young people and entice them to sexual acts at the expense of their "innocence," and their success if they then fail to complete their education successfully [17]. Eventually, this trend tends to affect the education system. Some students infected with HIV can easily transmit it to their fellow students who may be in a sexual relationship with them. Should they get ill from any opportunistic infection, they tend to perform poorly academically because of their illness.

Furthermore, social networks have been discovered to be associated with different forms of trickery that continuously leave the majority of young female adults as the victims of sexual abuse. This type of social network, to a larger extent, has been known to have been an agent for female CSW as well as porn stars. According to Chukwuka, there have been reports in Nigeria that cybercrimes are not the only activity that the Internet has introduced to Nigerians, there have also been many cases of Internet job seeking for CSW in and outside Nigeria [34]. The majority of people involved are innocent young adults aged between 17 and 30 years old. This is an age group normally expected to be enrolled at secondary and tertiary school levels.

Social media (social networking websites) appears to be a new approach to technology-based interventions in reducing the spread of HIV and other STI; it is a valuable tool for reaching and sensitizing millions of young people online to avoid engaging in risky sexual behavior. By doing so, we can reduce the spread of new HIV infections among youth in higher learning institutions. With social media's educational possibilities in mind, public health groups can invest significant time and money into their Facebook pages and YouTube channels with the hope of increasing HIV testing rates and reducing transmission. A good example is The African-American Office of Gay Concerns in Newark, New Jersey, which is one of several nonprofit groups experimenting with social networking to reach vulnerable populations such as teenagers [35]. Like any other social problem, the solution will not come overnight. More studies will have to be undertaken to determine just how deep the problem is and what measures to take to reverse these findings.

To address this problem, the following measures were recommended. First, social networks should be used to help young people to freely share and access information on HIV/AIDS. Second, linking to the Facebook group via UNZA's homepage, which includes a question and answer section for students to look for guidance and counseling. It has been argued that some students feel hesitant 
about approaching the counseling center for advice; therefore, such a platform will be ideal for these students to address their concerns. The e-mail addresses of the counselors, medical doctors, and lecturers should also be included in the Facebook page. To maintain secrecy, each student will have his or her own password and the response shall be directed to the sender.

Third, in addition, the Workmate Association, which looks at the welfare of the workers and links the workers to each other on HIV/AIDS issues, should work together with the students' union body to sensitize students on such matters. Finally, with social media's educational possibilities in mind, public health groups and educationists can invest significant time and money into these networks with the hope that it will increase HIV testing rates and reduce virus transmission.

\section{References}

[1] Coombe, C. and Kelly, M.J. (2001) Education as a Vehicle for Combating HIV/ AIDS. Prospects, 31, 438-445.

[2] UNAIDS (2013) AIDS by the Numbers. UNAIDS, Geneva.

[3] UNAIDS (2013) UNAIDS Report on the Global AIDS Epidemic, 2013. UNAIDS, Geneva.

[4] Ministry of Health (MOH) (2001) Zambia Demographic Health Survey. MOH, Lusaka.

[5] MOH (2009) Zambia Demographic Health Survey. MOH, Lusaka.

[6] Malungo, R.S. (2006) Report on 2006 Baseline Sexual Behaviour Survey among University of Zambia Students. For the Vice Chancellor Standing Committee on HIV and AIDS. University of Zambia, Lusaka.

[7] National HIV/AIDS/STI/TB Council (2009) The HIV/AIDS Epidemic in Zambia. USAID, Lusaka.

[8] Baker, D.P., Collins, J.M. and Leon, J. (2008) Risk Factor or Social Vaccine? The Historical Progression of the Role of Education in HIV and AIDS Infection in Sub-Saharan Africa. Prospects, 38, 467-486.

https://doi.org/10.1007/s11125-009-9097-y

[9] Gareth, M. (2009) Attitudes and Beliefs about HIV/AIDS Behaviour and Education among Tanzanian Youth. Sexual Health, 6, 293-299. https://doi.org/10.1071/SH08055

[10] Marino, K. (2012) Social Media: The New News Source. QuinStreet, Inc., Foster City. http://www.schools.com

[11] Presario, G. (2007) Mandatory Testing and Disclosure; Health and Wellness. UNAIDS, London.

[12] Zulu, M. (2013) Facebook Exposes Adulterous Woman. Sunday Mail, 21 July 2013.

[13] Haour-Knipe, M., de Zalduondo, B., Samuels, F., Molesworth, K. and Sehgal, S. (2013) HIV and "People on the Move": Six Strategies to Reduce Risk and Vulnerability during the Migration Process. International Migration, 52, 9-25. https://doi.org/10.1111/imig.12063

[14] Munachaka, J. (2006) Teachers' Vulnerability to HIV/AIDS Infection: The Case of Lusaka. University of Zambia, Lusaka.

[15] Potterat, J.J. (1999) Network Structural Dynamics and Infectious Disease Propaga- 
tion. International Journal of STD and AIDS, 10, 182-185.

https://doi.org/10.1258/0956462991913853

[16] Tyler, K. and Melander, L. (2011) The Effect of Drug and Sexual Behaviours with Social Network and Non-Network Members on Homeless Youths' Sexually Transmitted Infections and HIV Testing. Macmillan Education Limited, New York.

[17] Peter, C. (2010) World Failing to Meet 2010 HIV/AIDS Care Target: UN. UNAIDS, New York.

[18] Noar, S.M., Black, H.G. and Pierce, L.B. (2009) Efficiency of Computer Technology-Based HIV Prevention Interventions: A Meta Analysis. AIDS, 23, 107-115.

[19] Heckathorn, D.D., Broadhead, R.S., Anthony, D.L. and Weakliem, D.L. (1999) AIDS and Social Networks: HIV Prevention through Network Mobilization. Sociological Focus, 32, 159-179. https://doi.org/10.1080/00380237.1999.10571133

[20] Bull, S.S., Levine, D.K., Black, S.R., Schmiege, S.I. and Santelli, J. (2012) Social Media-Delivered Sexual Health. American Journal of Preventive Medicine, 43, 467474. https://doi.org/10.1016/j.amepre.2012.07.022

[21] Health Resources and Services Administration (HRSA) (2011) Social Media and HIV. HRSA, HIV/AIDS Bureau, U.S. Department of Health and Human Services, Rockville, MD.

http://www.incarecampaign.org/files/using-social-media-and-retention/hrsa-care-a ction-social-media/

[22] Lipowicz, A. (2009) NIH Funds a Facebook for Scientists. FCW. Vienna, VA. http://fcw.com

[23] Mendelsohn, J.B., Schilperoord, M., Spiegel, P. and Ross, D.A. (2012) Adherence to Antiretroviral Therapy and Treatment Outcomes among Conflict-Affected and Forcibly Displaced Populations: A Systematic Review. Conflict and Health, 6, 9. http://www.conflictandhealth.com/content/pdf/1752-1505-6-9.pdf https://doi.org/10.1186/1752-1505-6-9

[24] Luxton, D.D., June, J.D. and Fairall, J.M. (2012) Social Media and Suicide: A Public Health Perspective. American Journal of Public Health, 102, S195-S200. https://doi.org/10.2105/AJPH.2011.300608

[25] Bull, S.S. and McFarlane, M. (2000) Soliciting Sex on the Internet: What Are the Risks for Sexually Transmitted Diseases and HIV? Sexually Transmitted Diseases, 27, 545-550.

[26] Garofalo, R., Herrick, A., Mustanski, B.S. and Donenberg, R.G. (2007) Tip of the Iceberg: Young Men Who Have Sex with Men, the Internet, and HIV Risk. American Journal of Public Health, 97, 1113-1117. https://doi.org/10.2105/AJPH.2005.075630

[27] Carville, O. (2013) Syphilis "Back with a Vengeance". http://www.stuff.co.nz/national/health/8402842/Syphilis-back-with-a-vengeance

[28] Derbyshire, D. (2009) Social Websites Harm Children's Brains: Chilling Warning to Parents from Top Neuroscientist. Daily Mail, 24 February 2009.

[29] Tumfweko (2011) 15 Yr Old Lake Road Student Hangs Herself to Death Shortly after Quarrel with Dad. http://www.tumfweko.com/

[30] Alford, A. (2012) Social Media Fueling Teacher \& Student Sexual Relationships. Fox23.com, 29 May 2012. http://www.fox23.com

[31] Fowler, J.H. (2010) Examining Dynamic Social Networks and Human Behaviour. Little Brown and Co., New York.

[32] Hegdahl, H.K., Fylkesnes, K.M. and Sandøy, I.F. (2016) Sex Differences in HIV Prevalence Persist over Time: Evidence from 18 Countries in Sub-Saharan Africa. 
PLoS ONE, 11, e0148502. https://doi.org/10.1371/journal.pone.0148502

[33] Shiferaw, Y., Alemu, A., Assefa, A., Tesfaye, B., Gibermedhin, E. and Amare, M. (2014) Perception of Risk of HIV and Sexual Risk Behaviors among University Students: Implication for Planning Interventions. BMC Research Notes, 7, 162. https://doi.org/10.1186/1756-0500-7-162

[34] Chukwuka, P.O. (2001) Treatment Options. USAIDS, Lagos.

[35] Caputo, A. (2010) Problems and Emerging Approaches in HIV/AIDS Vaccine Development. National AIDS Center, Rome.

Submit or recommend next manuscript to SCIRP and we will provide best service for you:

Accepting pre-submission inquiries through Email, Facebook, LinkedIn, Twitter, etc. A wide selection of journals (inclusive of 9 subjects, more than 200 journals) Providing 24-hour high-quality service User-friendly online submission system Fair and swift peer-review system Efficient typesetting and proofreading procedure Display of the result of downloads and visits, as well as the number of cited articles Maximum dissemination of your research work

Submit your manuscript at: http://papersubmission.scirp.org/

Or contactwja@scirp.org 